of plant specimens - in Europe and North America peaked in 1990.

Research in the life sciences is not created or destroyed: it simply shifts from one form to another. As natural history has been deemphasized, molecular biology, genetics, experimental biology and ecological modelling have flourished. But here is the problem: many of those fields ultimately rely on data and specimens from natural history. Natural-history observations help to fight infectious diseases that cycle through different species, to identify promising leads for drug discovery, to manage fisheries and forests and other natural resources and to conserve species and ecosystems.

As Tewksbury and his colleagues write: "Direct knowledge of organisms - what they are, where they live, what they eat, why they behave the way they do, how they die - remains vital to science and society." The best algorithms in the world will fail to guide our action accurately if they are not based on a firm understanding of what is out there and what it's up to.

Revitalizing natural history will require tweaking the research incentives of grants and academic tenure. The BioScience article is right to call for natural historians to go out and stress the enduring importance of their craft to universities, funding agencies, foundations and the public. No biology student should get a diploma without at least a single course in identifying organisms and learning basic techniques for observing and recording data about them. Top journals should publish excellent natural history; the revived 'Natural History Miscellany' section in American Naturalist is a good first step.

Natural history itself can adapt to help. It should continue to expand beyond the elite, lone naturalist. New digital tools, including mobile versions of field guides (such as the Leafsnap app, which can identify tree species from photographs, and the Chirp! app, which helps users to recognize bird songs), are lowering the bar for entry for those without training. And digital data repositories - such as eBird,

"No biology
student should
get a diploma
without at least
a single course
in identifying
organisms."
created by the Cornell Lab of Ornithology in Ithaca, New York, and the New York-based National Audubon Society - mean that today's naturalists can share and compare their observations. These tools can be used by the general public to build big data sets, which can feed into experiments or models.

As scientists from Yale University point out in a Comment piece on page 33, such data sets are also crucial for other purposes: to hold to account the official government figures that, for one reason or another, do not accurately reflect the situation on the ground, in the air or in the seas.

Natural history has never been just about the science. It is a craft and a passion with its own immediate aesthetic and visceral pleasures, the epitome of a positive relationship with nature. The smartphone, as the most ubiquitous representative of an increasingly digital culture, has often been held up as the pernicious opposite of a direct relationship with the natural world. But technology can be used as a tool to draw us closer to nature as well as a screen to block our view.

The dedicated observers are still there. They tramp through the woods on cold winter nights, their breath visible in the moonlight. They play the calls of the great horned owl on their smartphones. And the great horned owls call back.

\section{Brain waves}

\section{Above the 'big neuroscience' commotion, literature plays its part.}

"L iterature was not born the day when a boy crying 'wolf, wolf' came running out of the Neanderthal valley with a big grey wolf at his heels," wrote novelist Vladimir Nabokov. Instead, he argued, it was born "on the day when a boy came crying 'wolf, wolf' and there was no wolf behind him".

The French consciousness-research pioneer Stanislav Dehaene uses this quote in his new book, Consciousness and the Brain, in which he describes his 'global neuronal workspace' theory, elaborated together with Jean-Pierre Changeux through modelling a 20 -year series of daring experiments probing conscious and unconscious perception in humans. Only since brain imaging and other tools have allowed us to view the human brain at work has it become 'respectable' to try to pin down consciousness, and to debate how the human mind has allowed the development of intellectual pursuits as sophisticated as literature.

The Dehaene-Changeux theory holds that awareness moves from subconscious to conscious only when we pay attention to specific sets of information in our brains: images, memory, emotional state. These briefly come together in a limited-capacity workspace, ready to broadcast to all brain regions through axons. This theoretical workspace is where consciousness emerges; where, for example, a storyteller may invent a fictitious scene of deceit, such as the boy who cried wolf.

Dehaene quotes Nabokov often in his books, with good reason. The poetic, multilingual novelist and entomologist often pondered eloquently on the state of being conscious. Understanding consciousness and the mind may take a century, but it stands as an irresistible beacon. Other goals, such as understanding, fixing or ameliorating neurodegenerative or psychiatric diseases, may be 'only' decades away.

Many regret, but few doubt, that the long haul towards these goals requires a cultural shift in neuroscience research, from small to big

science. Indeed, 'big neuroscience' has already begun. Last year, Europe formally launched its highly ambitious Human Brain Project (HBP), which aims to simulate the human brain in a supercomputer. It already has 32 partners across 13 countries. And the Brain Research through Advancing Innovative Neurotechnologies (BRAIN) Initiative, announced by US President Barack Obama on 2 April last year, will soon begin distributing money.

The privately funded Allen Institute for Brain Science in Seattle, Washington, has been doing big neuroscience for more than a decade, producing systematic anatomical and brain maps, mostly in the mouse, and is now starting to map functions of the component neurons. All of its maps are publicly available. It is a happy coincidence that Nature has published two brain-mapping papers from Allen scientists on the anniversary of Obama's announcement (see http://dx.doi.org/10.1038/ nature13185; http://dx.doi.org/10.1038/nature13186; 2014). One of the maps is the first gene-expression atlas of the entire developing human brain. The other is a mouse 'connectome' - the first brain-wide neuronal-connectivity map for a mammalian species - that will guide the initial modelling of the HBP, which is beginning with the mouse brain.

But the path to generating and modelling the data needed to crack the codes of the brain will not be smooth. Already, the HBP has annoyed researchers by not funding the generation of data in non-human primates in its first phase, perhaps fearing a political backlash. But monkey data will be needed as a bridge between the mouse and human brain.

As big neuroscience advances, the Dehaene-Changeux theory may be proved wrong. So, too, may the more abstractly mathematical 'integrated information theory' of consciousness preferred by the Allen Institute's chief scientific officer Christof Koch. That is the process of science. Koch complains in his review of Dehaene's new book in Science that the workspace theory limits itself too much to the waves of electrical activity in the brain that experiments pick up, and fails to explain the 'why' of consciousness (see http://doi.org/r5q; 2014). Koch counter-quotes Nabokov: "The breaking of a wave cannot explain the whole sea."

$\rightarrow$ NATURE.COM To comment online, click on Editorials at: go.nature.com/xhunqv
As big-brain programmes navigate their thorny early years, it is good to be so neatly reminded of their ultimate goal. 